\title{
MJN ETHICAL LEADERSHIP IN NURSING DURING THE COVID-19 PANDEMIC
}

\author{
Yusrita Zolkefli \\ IHS Research Ethics Committee, PAPRSB Institute of Health Sciences, Universiti Brunei Darussalam, Brunei \\ Corresponding Author's Email: yusrita.zolkefli@ubd.edu.bn
}

\section{Dear Editor,}

I am writing to you about ethical leadership in nursing during the COVID-19 pandemic. The challenges posed by the pandemic have been incredible, especially for nursing staff who have been on the front line since day one, and I believe this calls for a balance of moral courage and moral distress. I propose that recognising moral distress is key for nurse leaders, yet it is vital and courageous to strive to do the right thing always, especially during and after the pandemic crisis.

It is a nurse's ethical duty to help patients. However, such problems as insufficient PPE and bed crises may lead to moral distress, not to mention physical exhaustion. Long working hours, shift work, high workload, and other psychosocial hazards can lead to fatigue, occupational burnout, increased psychological distress, or declining mental health, affecting both health workers' health and the quality and safety of care delivered (WHO, 2020). At this point, nurses' moral courage and resilience are most invoked. Nevertheless, the worry remains, how much longer can nurses stay resilient, and what role do nurse leaders play in ensuring such resilience?

A nurse leader must ensure that everything is done to protect nurses' safety and well-being without compromising patient safety. A nurse leader has a moral duty to build a good ethical practice climate - in other words, an environment where poor or unethical practices are not cheered. For example, an overwhelmed staff member can err and potentially injure a patient. In this instance, the nurse leader is responsible for ensuring fair work delegation to ensure adequate rest for staff. It is equally crucial for the nurse leader to be open and welcome staff to share any ethical concerns. So, they do not feel they are walking alone during this crisis. An appropriate communication climate in the workplace is provided by ethical leaders who have excellent communication with their followers (Brown \& Trevino, 2006; Makaroff et al., 2014).

It is also important to ensure that nurses stay resilient and brave. How can that commitment be realized? One way is for the nurse leader to model professional conduct and promote ethical behaviour among nurses. Leaders need to do something to foster an ethical environment (Makaroff et al., 2014) whose culture makes it clear to staff that ethics matters to them. Furthermore, a positive environment can be compromised when there are conflicts between staff members. As much as a win-win situation is the goal, there are times when this is almost impossible. Ethical leaders must seek to model and foster ethical success (Storch et al., 2013), while at the same time responding to moral issues and improving nurses' efficiency by fostering respect for human beings. Nurse leaders must continue to promote ethical principles and values. Ethical leaders often seek to improve wrong actions or outcomes by raising awareness of the consequences, encouraging people to change their behaviour, and providing incentives to learn the right practices, as well as being firm in dealing with errors. Leadership also plays a role in building a caring culture (Gustafsson \& Stenberg, 2017), and leadership ethics and trust are core components of a healthy work environment culture (Gallagher \& Tschudin, 2010).

Last but not least, ethical leadership has a positive effect on the nurse leader and the workforce in most instances. Given the current crisis, it is equally crucial for nurse leaders to take care of themselves as well. It may always be emotionally and physically challenging to be viewed as a role model and to behave with dignity. It is important to remember that nursing leaders themselves are often fragile.

Yusrita Zolkefli 


\section{REFERENCES}

Brown, M. E. \& Treviño, L. K. (2006). Ethical leadership: A review and future directions. The Leadership Quarterly, 17(6), pp 595-616. doi:10.1016/j.leaqua.2006.10.004

Gallagher, A. \& Tschudin, V. (2010), Educating for ethical leadership. Nurse Education Today, 30(3), pp 224-227. doi: 10.1016/j.nedt.2009.11.003.

Gustafsson, L.-K. and Stenberg, M. (2017). Crucial contextual attributes of nursing leadership towards a care ethics. Nursing Ethics, 24(4), pp 419-429. doi: 10.1177/0969733015614879.

Makaroff, K. S., Storch, J., Pauly, B. \& Newton, L. (2014). Searching for ethical leadership in nursing. Nursing Ethics, 21(6), pp 642-658.doi: 10.1177/0969733013513213.

Storch, J., Makaroff, K. S., Pauly, B. \& Newton, L. (2013). Take me to my leader: the importance of ethical leadership among formal nurse leaders. Nursing Ethics, 20(2), pp150-157.

World Health Organization WHO (2020). WHO calls for healthy, safe and decent working conditions for all health workers, amidst COVID-19 pandemic (Accessed $1^{\text {st }}$ July 2020). Retrieved from: https://www.who.int/newsroom/detail/28-04-2020-who-calls-for-healthy-safe-and-decent-working-conditions-for-all-health-workers-amidstcovid-19-pandemic 